\begin{abstract}
(2.
THE NATURAL UNEMPLOYMENT RATE IN AUSTRLIA SINCE THE SEVENTIES
\end{abstract}

by

Nicolaas Groenewold

A.J. Hagger

DISCUSSION PAPER 97.24

DEPARTMENT OF ECONOMICS

THE UNIVERSITY OF WESTERN AUSTRALIA

NEDLANDS, WESTERN AUSTRALIA 6907

ISSN 0811-6067

ISBN 0-86422-815-5 


\title{
THE NATURAL UNEMPLOYMENT RATE IN AUSTRALIA SINCE THE SEVENTIES
}

\author{
by \\ Nicolaas Groenewold* \\ Department of Economics \\ The University of Western Australia \\ and \\ Centre for Regional Economic Analysis \\ University of Tasmania \\ and \\ A.J. Hagger \\ Centre for Regional Economic Analysis \\ University of Tasmania
}

DISCUSSION PAPER 97.24

October 1997

ISSN 0811-6067

ISBN 0-86422-811-815-5

* Corresponding author. We are grateful for financial support from the Strategic Research Fund at the School of Commerce and Law, University of Tasmania. 


\begin{abstract}
The natural rate of unemployment is calculated based on Lilien's(1982) notion that an increase in the sectoral dispersion of demand results in a rise in unemployment for a given level of aggregate demand. In contrast to earlier applications, the dispersion measure is based on sectoral employment growth rates purged of aggregate influences using a VAR model. We find that most of the rise in unemployment in Australia since the 1970s reflects the increase in the underlying natural rate. This finding is broadly consistent with Lilien's results for the US as well as earlier results for Australia and Canada.
\end{abstract}

JEL Classifications E3 J6

Key Words: natural unemployment rate, demand dispersion 


\section{Introduction}

Since the mid 1970s all industrialised countries of the Western world have experienced a marked and sustained upward movement in their unemployment rate. The Australian record is typical. In the first half of the 1970s our unemployment rate fluctuated around a figure of 2 to 3 per cent. By 1976 the rate had climbed to a new plateau of about 5 to 6 per cent, a level maintained for the rest of the decade. The early 1980s saw a second jump to a figure somewhat in excess of 10 per cent - a level maintained until around the end of 1983. The rest of the 1980s saw a return to the rates ruling in the late 1970 s, but the 10 per cent plateau was restored in the early nineties and has been maintained ever since.

Not surprisingly, this striking phenomenon led to extensive research, particularly in the 1980s. This research followed several paths. One of particular note originated with the seminal paper of Lilien (1982).

The background to Lilien's paper was as follows. He argued that the unemployment rate can be thought of as consisting of two components: one which captures the influence on the unemployment rate of changes in the level of aggregate demand and the other which captures the influence of changes in the composition of aggregate demand. The question which Lilien posed was an empirical one. Was the long-run upward movement in the US unemployment rate in the post-war period attributable to the first component or to the second? Was it due to a persistent deficiency in the level of aggregate demand or was it the outcome of changes in the composition of aggregate demand?

Another way of stating Lilien's question is in terms of the concept of "the natural rate". Though the term, "natural rate", is not consistently used, most of those who employ the concept have in mind that part of the movement in the unemployment rate which is attributable to causes other than movements in aggregate demand.

If the natural rate, defined in this way, is denoted by $U^{*}$ and the actual unemployment rate by $U$, then the aggregate-demand component of the unemployment rate must be (U-U*). Lilien's question can be re-phrased, then, as follows: Was the long-run upward movement in the US unemployment rate the outcome of a comparatively steady $U^{*}$ coupled with an increasingly positive (U-U*) 
or was it the outcome of a steadily rising $U^{*}$, coupled with a (U-U*) sometimes positive and sometimes negative? In the first case aggregative influences would provide the bulk of the explanation of the long-term rise in the unemployment rate; in the second case compositional influences. ${ }^{1}$

The broad strategy which Lilien devised to tackle this empirical question was to begin by setting up a labour-market model having the unemployment rate $(\mathrm{U})$ as one of its endogenous variables and a measure of demand-shifts between industries $(\sigma)$ as one of its exogenous variables. He then used this model to solve for $U$ in terms of exogenous and lagged-endogenous variables and proceeded to estimate the resulting unemployment equation from time-series data. The estimated unemployment equation was the numerical tool which Lilien used in order to answer his question. The answer he obtained was that the long-term rise in the US unemployment rate was very largely due to a rise in the natural rate; aggregative influences played a comparatively minor role.

Lilien's paper gave rise to an extensive literature to which contributions are still being made. There has been general agreement by those who have contributed to this literature that a valid econometric procedure which enabled the unemployment rate to be decomposed into its "natural rate" and residual (aggregative) components would be a useful policy tool, if only because the policies required to reduce the former component are very different from those which are required to reduce the latter. On the other hand, there has been widespread dissatisfaction with the particular procedure which Lilien used. Lilien's critics have fallen into two broad groups. One group consists of those who have been dissatisfied with the model of labour-market flows from which Lilien's unemployment equation - the cornerstone of his procedure - was derived. These authors have set out to develop a broader and more detailed model of labour-market flows which would show the link between $U$ and its determinants in a more satisfactory way. Included in this group are Murphy and Topel (1987), Juhn, Murphy and Topel (1991), Davis (1987), Blanchard and Diamond (1989), Norrbin and Schlagenhauf $(1988,1991)$ and Parker (1992). The other group comprises authors who have been prepared to accept Lilien's model but who have been unhappy with the way in which he devised series for two unobservable variables which appear among the explanatory variables in his unemployment equation. Only when series had been constructed for both variables could the unemployment equation 
be estimated and the "natural-rate" question be answered. Members of this group include Abraham and Katz (1985), Loungani (1986), Neelin (1987), Palley (1992), Mills, Pelloni and Zervoyianni (1995), Loungani, Rush and Tave (1990) and Brainard and Cutler (1993).

One aim of the present paper is to make a further contribution on the methodological side. We do this in section 2. We accept Lilien's model of labourmarket flows and join those critics who focus on the way in which he constructs series for the two unobservable variables referred to earlier. Our contribution consists of devising methods for carrying out this task which we believe to be superior to any so far proposed. We also put our methods to work to build up Australian series for both unobservables.

The second and main aim of the paper is to answer Lilien's "natural-rate" question for Australia. We carry out this task in section 3 by estimating a Lilien-type unemployment equation from Australian data including the two Australian series derived in section 2. The conclusion we reach is that the long-term rise in Australia's unemployment rate since the 1970 s was almost entirely due to a rise in the natural rate; aggregative influences played a negligible role. ${ }^{2}$ This conclusion has strong implications for macroeconomic policy in Australia which we spell out.

In the final section of the paper we present a brief summary of the preceding sections, draw attention to the limitations of our work and point to possible ways in which it might be extended.

\section{The Unemployment Equation : Specification}

As explained in section 1, we intend to use Lilien's model of labour-market flows and the unemployment equation which it yields as the basis for answering his "natural-rate" question for Australia. Our methodological contribution relates not to the structure of the unemployment equation but to the series which are used when it comes to estimation of two unobservable variables which appear in the unemployment equation. Before proceeding, therefore, we need to briefly discuss the Lilien model and the derivation of the unemployment equation which it implies.

Lilien starts with the flow identity

$$
\Delta \mathrm{U}_{\mathrm{t}}=\theta_{1 \mathrm{t}}-\theta_{2 \mathrm{t}}
$$


where $U$ is the unemployment rate and the $\theta \mathrm{s}$ are, respectively, the flow into unemployment and the flow out of unemployment. Both are rates.

The flow into unemployment, $\theta_{1}$, is modelled by:

$$
\theta_{1 \mathrm{t}}=\mathrm{L}_{\mathrm{t}}+\left(\mathrm{a}_{0}+\mathrm{a}_{1} \mathrm{Q}_{\mathrm{t}}+\eta_{1 \mathrm{t}}\right)
$$

where $\mathrm{L}$ is the layoff-flow into unemployment and the bracketed term is the non-layoff-flow into unemployment. In the bracketed term $Q$ denotes quits, $a_{0}$ and $a_{1}$ are constants and $\eta_{1}$ is a random disturbance. Both $L$ and $Q$ are rates. Throughout the following, lower case letters will denote constants and $\eta$ a random disturbance.

$\mathrm{L}$ and $\mathrm{Q}$ are determined by

$$
\begin{aligned}
& \mathrm{L}_{\mathrm{t}}=\mathrm{b}_{0}+\mathrm{b}_{1}\left(\Delta \mathrm{E}_{\mathrm{t}}+\mathrm{Q}_{\mathrm{t}}\right)+\mathrm{b}_{2} \sigma_{\mathrm{t}}+\eta_{2 \mathrm{t}} \\
& \mathrm{Q}_{\mathrm{t}}=\mathrm{c}_{0}+\mathrm{c}_{1} \mathrm{U}_{\mathrm{t}}+\eta_{3 \mathrm{t}}
\end{aligned}
$$

where $\Delta \mathrm{E}$ is the change in the employment rate and $\sigma$ denotes the extent of demandshifts between industries. The sign of $c_{1}$ is negative.

The sign of $b_{2}$ is positive. $L$ is held to be positively related to ? because the greater the extent of demand-shifts between industries the greater the dispersion of industry growth rates. And the greater the dispersion of industry growth rates the greater the layoff rate. As Lilien puts it, "far fewer layoffs would be generated in an economy where employment was growing at 2 percent per year in all firms than would be generated in an economy where employment was growing at 8 percent per year in half of all firms and by -4 percent in the remaining firms, despite the fact that both economies would have identical aggregate growth rates. ${ }^{13}$

The flow out of unemployment, $\theta_{2}$, is modelled by:

$$
\theta_{2 t}=\alpha U_{t-1}+\sum_{i=0}^{k} \beta_{i} A_{t-i}+\eta_{4 t}
$$

where A denotes the strength of aggregate-demand pressure.

The final equation of the model is the identity

$$
E_{t}+U_{t}=1
$$

The exogenous variables are $\sigma$ and $A$. The solution of the model for $U$ in terms of $\sigma$ and $A$ (the reduced-form equation for $U$ ) is:

$$
\mathrm{U}_{\mathrm{t}}=\delta_{0}+\delta_{1} \sigma_{\mathrm{t}}+\sum_{\mathrm{i}=0}^{\mathrm{k}} \lambda_{\mathrm{i}} \mathrm{A}_{\mathrm{t}-\mathrm{i}}+\delta_{2} \mathrm{U}_{\mathrm{t}-1}+\eta_{\mathrm{t}}
$$


where the $\delta s$ and $\lambda s$ are constants and $\eta$ is a random disturbance. The estimated version of this relationship is the tool we use in the paper to answer Lilien's "naturalrate" question for Australia. Since the model is based largely on definitional stock and flow interrelationships in the labour market, it is likely to be as applicable to the Australian as to the US economy. Indeed, given its omission of any explicit attention to wages as an equilibrating variable in the labour market, it may be argued that it is more appropriate for the relatively regulated Australian market than the more flexible US market.

Before (1) could be estimated it was necessary to construct a series for each of the two unobservable variables, $\sigma$ and $A$. The main purpose of the present section is to explain the methods that were developed to perform this task and to apply those methods to Australian data. We begin by explaining how the $\sigma$ series was constructed.

\section{II.1 The $\sigma$ series}

To construct a series for $\sigma$ we took the procedure used by Lilien himself as a starting point. Lilien calculated his $\sigma$ series by means of (2):

$$
\sigma_{t}=\left[\sum_{i=1}^{n} s_{i t}\left(g_{i t}-g_{t}\right)^{2}\right]^{1 / 2}
$$

where $s_{i}$ is the ith industry's share of employment, $g_{i}$ is industry i's employment growth rate and $\mathrm{g}$ is the aggregate employment growth rate. The difficulty with a $\sigma$ series calculated from (2), however, is that while $\sigma$ will change in response to changes in the composition of aggregate demand it may, under certain circumstances, also change in response to a change in the pressure of aggregate demand.

This problem with the Lilien procedure was first noted by Abraham and Katz (1985). A possible way of dealing with the problem was suggested by Palley (1992). The essence of Palley's proposal was to retain (2) as the basis for calculating the $\sigma$ series but to remove all aggregate-demand influences from the employment growthrate series used in the calculation. He did this by estimating an equation of the form

$$
g_{i t}=a_{0 i}+a_{1 i} T+\sum_{j=1}^{4} a_{2 i, j} g_{i, t-j}+\sum_{j=1}^{4} a_{3 i, j} g_{-i, t-j}+e_{i t} \quad \mathrm{i}=1,2, \ldots \ldots, \mathrm{K}
$$

for each industrial sector (there are $\mathrm{K}$ of them) where $\mathrm{T}$ is a time trend and $\mathrm{g}_{\text {-it }}$ denotes the employment growth rate for all sectors other than sector i. The set of "purged" employment growth-rate series $\left(g *_{\text {it }}\right)$ were then calculated from 


$$
g^{*}{ }_{i t}=\hat{a}_{0 i}+\hat{a}_{1 i} T+\sum_{j=1}^{4} \hat{a}_{2 i, j} g_{i, t-j}+\hat{e}_{i t} \quad \mathrm{i}=1,2, \ldots \ldots, \mathrm{K}
$$

where ${ }^{\wedge}$ denotes "estimated".

This method is unsuccessful since from (4) it is clear that $g *_{i t}$ involves $g_{i, t-1}, g_{i, t-}$ 2, $g_{i, t-3}, g_{i, t-4}$. However, from (3) it is clear that $g_{i, t-1}$ involves $g_{-i, t-1}$. Similarly, $g_{i, t-2}$ involves $\mathrm{g}_{-\mathrm{i}, \mathrm{t}-2}$ and so on. In other words aggregative influences still remain in $\mathrm{g}_{\mathrm{it}}$ via the $g_{-i} \mathrm{~s}$. In the present paper we accept Palley's basic idea but reject his method of calculating the $\mathrm{g}^{*}$ it series. Instead we use a method based on the VAR model.

In outline our solution is as follows. We begin by postulating a 13-equation VAR model having, as variables, the current and lagged employment growth rates of the 13 ASIC Divisions. Thus our model is of the form:

$$
g_{i t}=\alpha_{0}^{i}+\sum_{j=1}^{J} \sum_{k=1}^{13} \beta_{j}^{i k} g_{k, t-j}+e_{i r}, i=1,2, \ldots, 13
$$

where the $\alpha$ s and the $\beta$ s are constant and the es are random errors, each with zero mean and constant variance. The VMA (Vector Moving Average) form of (5) is:

$$
g_{i t}=\delta_{0}^{i}+\sum_{j=0}^{\infty} \gamma_{j}^{i i} e_{i, t-j}+\sum_{j=1}^{\infty} \sum_{k=1, k \neq i}^{13} \gamma_{j}^{i k} e_{k, t-j}, i=1,2, \ldots, 13
$$

where the $\delta$ s and the $\gamma s$ are constants involving the $\alpha$ s and the $\beta$ s with $\gamma_{0}^{\mathrm{ii}}=1$. It can be seen that the third term on the right-hand side of (6) gives the impact made on $g_{i t}$ by influences which have shocked the employment growth rates of all industries except the ith, ie. by aggregative influences. Thus in contrast to Palley, we measure $\mathrm{g}_{\mathrm{it}}$ * by the first two terms in (6), i.e.

$$
\mathrm{g}_{\mathrm{it}}^{*}=\hat{\delta}_{0}^{i}+\sum_{j=0}^{\infty} \hat{\gamma}_{j}^{i i} \hat{e}_{i, t-j} \quad \mathrm{i}=1,2, \ldots ., 13
$$

Further details of the VAR model on which the above procedure is based are given in Appendix 1. The $\sigma$ series obtained by application of (2) is given in Appendix 2. 


\section{II.2 The A series}

As with the $\sigma$ series, our method of constructing a series for the unobservable variable, $\mathrm{A}$, was different to both Lilien's and Palley's.

The A series used by Lilien was one constructed by Barro (1977) to measure unanticipated policy changes. This approach to the construction of an A series is satisfactory only if two conditions are satisfied. In the first place policy changes must be the only source of change in aggregate-demand pressure. Secondly, unanticipated policy changes must be the only policy changes which result in a change in demand pressure. Neither condition is likely to be met. As for the first, demand pressure can change in a country not only because of policy changes but because of non-policy changes such as changes to world economic conditions and changes to business confidence. As for the second, the Sargent/Wallace "policy-ineffectiveness proposition" has been subjected to extensive testing and, in general, has been found wanting. ${ }^{4}$ For these reasons we rejected Lilien's approach to the construction of an A series.

We also rejected Palley's approach which was to use estimated versions of the $\mathrm{K}$ equations in (3) to calculate, for each sector, a series for the second summation on the right-hand side and then to use the $\mathrm{K}$ resulting series in (2) in place of the $\mathrm{g}_{i t}$ series.

This procedure has two main difficulties. The first is that the summation in question does not fully represent the aggregate demand influences on $\mathrm{g}_{\mathrm{i}}$. The second difficulty is that there is no reason to believe that changes in the dispersion of these series will be related in any definite way to changes in the pressure of aggregate demand.

We worked with two alternative series for $A$. The first was a series based on GDP in constant prices, namely, GDP in constant prices expressed as a ratio of potential (full employment) GDP in constant prices. Our interpretation of this series was that the higher the actual/potential real GDP ratio the greater the pressure of aggregate demand.

Our second A series was one calculated from the series already calculated for $\mathrm{g}_{\mathrm{it}}{ }^{*}$. The first step was to calculate a series for $\mathrm{g}_{\mathrm{it}} * *$ from

$$
\mathrm{g}_{\mathrm{it}}^{* *}=\mathrm{git}_{\mathrm{it}}-\mathrm{g}_{\mathrm{it}}{ }^{*}
$$


It will be clear from (6) and (7) that

$$
\mathrm{g}_{\mathrm{it}} * *=\sum_{\mathrm{j}=1}^{\infty} \sum_{\mathrm{k}=1, \mathrm{k} \neq \mathrm{j}}^{13} \hat{\gamma}_{\mathrm{j}}^{\mathrm{ik}} \hat{\mathrm{e}}_{\mathrm{k}, t-\mathrm{j}}, \quad \mathrm{i}=1,2, \ldots ., 13
$$

We then used the $\mathrm{g}_{\mathrm{it}}{ }^{* *}$ series to calculate a hypothetical economy-wide employment growth rate, denoted by $\mathrm{g}_{\mathrm{t}}{ }^{* *}$. This hypothetical growth-rate series, which is also given in Appendix 2, was our alternative A series. In the rest of the paper the first of the two $A$ series will be denoted by $A_{1}$ and the second by $A_{2}$.

III The Unemployment Equation : Estimation and Natural-Rate Results

In this section we estimate (1) with the $A_{1}$ version of the $A$ variable and use the estimated equation to derive a natural-rate series for Australia. Of the two measures of demand pressure, we prefer $A_{1}$ (the ratio of actual to potential GDP) since it is more easily interpretable and approximates more closely the commonly used conept of aggregate excess demand. We therefore proceed by using $A_{1}$ except when we test the robustness of our natural rate calculations.

Before proceeding with estimation, we examined $U, \sigma$ and $A_{1}$ from the standpoint of stationarity and co-integration. In recent years it has become clear that estimation of an equation whose variables are both non-stationary and not cointegrated raises serious problems. ${ }^{5}$ We wished to avoid those problems, should they be present, by carrying out the estimation with first differences of the variables rather than with the variables in their original form.

\section{III.1 Data}

For estimation and the preliminary stationarity/co-integration tests we used quarterly, seasonally-adjusted data for the period, 1979(4) to 1993(4). ${ }^{6}$ The series for U was obtained from the DXDATA data-base. ${ }^{7}$ As already mentioned the series for $\sigma$ is given in Appendix 2. The series for $A_{1}$ was also obtained from the DXDATA database where this variable is denoted by GUT.

All empirical results were obtained using Shazam 7.0. 


\section{III.2 Stationarity and Co-integration}

The first three lines of Table 1 show results of stationarity tests for $U, \sigma$ and $A_{1}$. Two tests were employed. They were the Augmented Dickey-Fuller test (ADF) and the Phillips-Perron test $(\mathrm{PP})^{8}$. Both tests included a trend term and were tests of a null hypothesis of difference-stationarity against an alternative of trend-stationarity. Results for the ADF test are shown in column 2 and for the PP test in column 3. The critical values listed in column 4 apply to both tests.

Table 1

Tests for Stationarity and Co-integration: Levels

\begin{tabular}{|c|c|c|c|}
\hline Variable & $A D F$ & $P P$ & 10\% Critical Value \\
\hline $\mathrm{U}$ & 3.62 & 1.14 & 5.34 \\
\hline$\sigma$ & 6.14 & 34.24 & 5.34 \\
\hline $\mathrm{A}_{1}$ & 3.53 & 3.44 & 5.34 \\
\hline $\mathrm{U}, \sigma, \mathrm{A}_{1}$ & -0.55 & -0.73 & -3.45 \\
\hline
\end{tabular}

It will be seen that only one of the variables $(\sigma)$ is stationary on both tests.

We therefore proceeded to test for co-integration with the results reported in the last line of Table 1. The test of cointegration excludes the trend term (since it is based on residuals). There is clear evidence against co-integration.

Having thus ruled out estimation in terms of the levels of the variables we proceeded to test for stationarity in terms of the first differences of the variables. The results of the stationarity tests are shown in Table 2 . It will be seen that, while only $\Delta \sigma$ is stationary on the ADF test, all three are stationary on the PP test.

Table 2

Tests for Stationarity: First Differences

\begin{tabular}{|c|c|c|c|}
\hline Variable & $A D F$ & $P P$ & 10\% Critical Value \\
\hline$\Delta \mathrm{U}$ & 3.71 & 6.43 & 5.34 \\
\hline$\Delta \sigma$ & 12.54 & 253.72 & 5.34 \\
\hline$\Delta \mathrm{A}_{1}$ & 4.61 & 35.04 & 5.34 \\
\hline
\end{tabular}

Though the evidence is not entirely conclusive, we concluded from the results of both tables that $U$ and $A_{1}$ are stationary in the first differences and that $\sigma$ is stationary both in the levels and the first differences. Purely statistical considerations 
suggest an equation regressing $\Delta \mathrm{U}$ on $\Delta \mathrm{A}_{1}$ and $\sigma$. This formulation was rejected, however, since it makes no economic sense. Since $\sigma$ is always positive, a situation in which there was no demand pressure $\left(A_{1}=0\right)$ and a constant (but positive) $\sigma$ would results in a positive $\Delta \mathrm{U}$, i.e. an ever-growing unemployment rate. It is more in keeping with the spirit of Lilien's analysis that a constant $\sigma$ and no demand pressure would results in a constant unemployment rate. To ensure this we specified the equation in terms of the first differences of all the variables.

\section{III.3 Estimated Equation}

Determination of an appropriate lag structure for our unemployment equation and estimation of the equation, went hand-in-hand. Our procedure was in the spirit of the "Hendry approach" to start with an equation with four lags on all variables, including the lagged dependent variable and then, using OLS, to systematically eliminate all insignificant variables. The estimated equation which finally emerged from this procedure was

$$
\begin{aligned}
& \Delta \mathrm{U}_{\mathrm{t}}=0.0753+0.3359 \Delta \mathrm{U}_{\mathrm{t}-1}+0.1641 \Delta \sigma_{\mathrm{t}}-13.743 \Delta \mathrm{A}_{1, \mathrm{t}}-13.820 \Delta \mathrm{A}_{1, \mathrm{t}-\mathrm{l}}-8.0082 \Delta \mathrm{A}_{1, \mathrm{t}-3} \\
& \begin{array}{lllll}
(1.817) & (3.049) & (2.368) & (-3.524) & (-3.660)
\end{array} \quad(-3.327) \\
& \mathrm{R}^{2}=0.5511 ; \quad \mathrm{DW}=2.1146 \quad \text { Durbin } \mathrm{h}=-0.9932
\end{aligned}
$$

The equation is satisfactory on all the usual criteria: all explanatory variables have the correct sign and all have healthy t-ratios; the Durbin-h statistic gives little indication that relevant explanatory variables have been omitted; finally, having regard to the fact that estimation is in the first-differences of the variables, $R^{2}$ is more than satisfactory.

Two caveats are in order regarding equation (10). First, it is well-known that a sequential specification search such as that underlying equation (10), while common practice, involves t-tests which at successive stages have actual size which may differ from the nominal significance level and the t-statistics ought to be interpreted with some caution. Second, another potential problem is that associated with generated regressors. ${ }^{10}$ It could be argued that the standard errors for the regressors in (10) are misleading since the both $\mathrm{A}$ and $\sigma$ are generated although in a more complicated fashion than any of the cases reviewed in Oxley and McAleer (1993). Standard 
procedures are therefore not available for correcting the standard errors in this case. In assessing the importance of these two caveats for the results, it should be recalled that the focus of the paper is on calculating the natural rate rather than testing the sectoral-shift hypothesis and t-tests are used only to determine the final specification of the unemployment equation. Work with US data reported in Groenewold and Hagger (1997) shows that whether insignificant variables are retained has little effect on the resulting natural-rate series.

\section{III.4 Natural-rate Series}

To generate a natural-rate series from (10) we followed Lilien and Palley in defining the natural-rate for quarter $t$ (denoted by $U_{t}^{*}$ ) as the value of $U_{t}$ that would have been observed if the pressure of aggregate demand had remained constant over the sample period.

With this definition, calculation of a natural-rate series from (10) was merely a matter of replacing $\Delta \mathrm{U}_{\mathrm{t}}$ and $\Delta \mathrm{U}_{\mathrm{t}-1}$ by $\Delta \mathrm{U}_{\mathrm{t}}^{*}$ and $\Delta \mathrm{U}_{\mathrm{t}-1}^{*}$ and putting all $\Delta \mathrm{A}_{1} \mathrm{~s}$ equal to zero. This gave

$$
\Delta \mathrm{U}_{\mathrm{t}}^{*}=0.0753+0.3359 \Delta \mathrm{U}_{\mathrm{t}-1}+0.1641 \Delta \sigma_{\mathrm{t}}
$$

which implies

$$
\mathrm{U}_{\mathrm{t}}^{*}=0.0753+1.3359 \mathrm{U}_{\mathrm{t}-1}^{*}-0.3359 \mathrm{U}_{\mathrm{t}-2}^{*}+0.1641 \Delta \sigma_{\mathrm{t}}
$$

Equation (12) was the expression used to calculate the natural-rate series for the March quarter 1980 through the December quarter 1993. (The March quarter 1980 was the first quarter for which an observation on $\Delta \sigma$ was available.) To "start up" the calculation it was necessary to make assumptions about $U^{*}$ in the September and December quarters 1979. The assumption made was that both $U^{*}(1979(3))$ and $U^{*}$ (1979(4)) were equal to $U(1979(3))$.

The $U^{*}$ series generated in this way is shown in Figure 1 together with the $U$ series. The two series themselves are reported in Appendix 2.

It will be recalled that in section 1 we argued that two different explanations could be advanced for the long-run rise in Australia's unemployment rate since the mid-1970s. The first was that it was the outcome of a comparatively stable $U^{*}$ series 


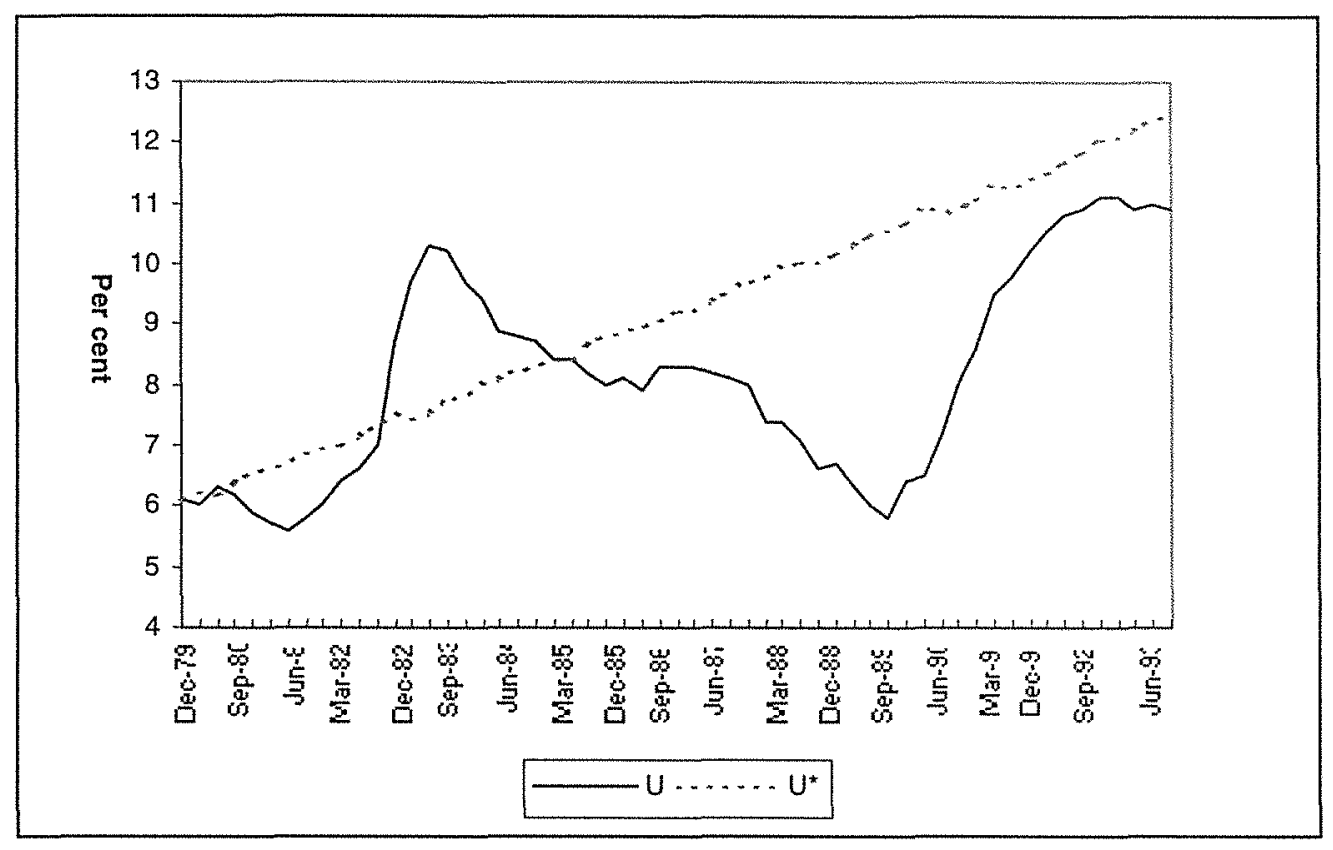

Figure 1. Unemployment Rate: Actual (U) and Natural (U*)

coupled with an increasingly positive $\left(U-U^{*}\right)$ series, ie. that the long-run rise in the unemployment rate was due primarily to a persistent deficiency of aggregate demand.

The second explanation was that the long-run rise in the unemployment rate was the outcome of a steadily rising $U^{*}$ series coupled with a $\left(U-U^{*}\right)$ series of alternating sign, ie. that the long-run rise in the unemployment rate was primarily due to a persistently decreasing natural rate, itself due, though not exclusively, to composition-of-demand influences.

The conclusion which emerges clearly from Table 3 and Figure 1 is that it the second explanation, not the first, which is valid. This result is consistent with that derived by Ooi and Groenewold (1992) for the period 1966-87. There the natural rate was based on a version of the model of Layard and Nickell (1985) and was found to more than explain the movement in the actual unemployment rate over the sample period. Ooi and Groenewold defined that natural rate as the rate of unemployment at which price expectations are realised and where aggregate demand is consistent with these realised expectations. They estimated that the natural rate rose from $0.6 \%$ in $1968-73$ to $5.68 \%$ in $1974-80$ and then to $9.52 \%$ in $1981-86$; the corresponding actual rates were $2.04 \%, 5.39 \%$ and $8.40 \%$ respectively. These figures are not dissimilar to estimates of the "structural unemployment rate" reported in the Reserve Bank of 
Australia (1993) which suggest that the structural rate rose sharply from about $2 \%$ in the early 1970 s to as high as $8 \%$ in the 1980 s.

Our conclusion has important implications for policy, both past and future. Beginning with the past, let us ask what the conclusion implies for macro-economic policy over the last two decades and, more specifically, for demand-management policy. In the first place there are clear implications for the nature of the task which the demand-management authorities faced over this period; their task was to offset the upward thrust on $\mathrm{U}$ imposed by $\mathrm{U}^{*}$ by means of a downward thrust via (U-U*). In other words their task was to avoid a persistently positive (U - U*) and if possible to keep $\left(U-U^{*}\right)$ persistently negative - to keep the actual rate more-or-less permanently below the natural rate. How successful were they? Here, too, our conclusion has definite implications. As Figure 1 shows, $\left(U-U^{*}\right)$ was negative (the unemployment rate was below the natural rate) for the entire period with the exception of the three years 1982 to 1985 . Thus it would appear that demandmanagement policy was highly successful, given that the authorities faced a steadily rising natural rate over which they had no control.

What of the future? The conclusion which emerges from Table 3 and Figure 1 implies that if we wish to get the unemployment rate down to the level of the early 1970s, we must achieve one of two things. Either we must find some way of reducing $\mathrm{U}^{*}$ or we must be even more successful in keeping $\mathrm{U}$ below $\mathrm{U}^{*}$ via demandmanagement policy, than we were in the last two decades. The former would appear to be the more promising route; it is to micro-policy that we should now be looking, not to macro-policy if we wish to improve our unemployment record.

\section{III.5 Robustness of Natural-Rate Results}

The natural-rate results shown in Table 3 and Figure 1 were derived using the series for the $A_{1}$ version of the A variable and the series for the VAR-based version of the $\sigma$ variable which was derived in section 2.1. We now examine the robustness of these results to the use of alternative $A$ and $\sigma$ series. The alternatives to the $A_{1}$ series which are explored are the series for $\mathrm{A}_{2}$ shown in Appendix 2 and series which we calculated in the manner of Palley, as described in section 2.2 This will be the referred to as the $A_{3}$ series. As an alternative to our $\sigma$ series (to be referred to 
henceforth as $\sigma_{1}$ ) we explore a series of the Palley-type (see section 2.2 once again) which we calculated and which will be referred to as $\sigma_{2}$.

The procedure used in our examination of robustness was to estimate an unemployment equation corresponding to (10) for three alternative combinations of $\mathrm{A}$ and $\sigma$ series and, in each case, to use the equation to generate a $U^{*}$ series. In every case the estimation was in first-difference form and the procedure described in section 3.3 in relation to (10) was used to find and estimate the preferred equation. Likewise the procedure used to generate the $U^{*}$ series from the preferred unemployment equation was in all cases the one described in section 3.4. The $U^{*}$ series which emerged for each combination of $A$ and $\sigma$ series is shown in Table 4. The $U^{*}$ series calculated from (10) is also shown for comparison (in the " $A_{1}, \sigma_{1}$ " column) as is the $U$ series. For ease of presentation the four $U^{*}$ series and the $U$ series are shown on an annual basis, the yearly figure being an unweighted average of the four quarterly figures. A comparison of the $\left(A_{1}, \sigma_{1}\right)$ and $\left(A_{1}, \sigma_{2}\right)$ columns indicates little effect of the definition of $\sigma$ and $A_{2}$ and $A_{3}$ are therefore reported only in combination with $\sigma_{1}$.

Table 4

Alternative $U^{*}$ Series

\begin{tabular}{|r|r|r|r|r|r|}
\hline Year & $\mathrm{U}$ & \multicolumn{5}{|c|}{$\mathrm{U}^{*}$} \\
\hline & & $\mathrm{A}_{1}, \sigma_{1}$ & $\mathrm{~A}_{1}, \sigma_{2}$ & $\mathrm{~A}_{2}, \sigma_{1}$ & $\mathrm{~A}_{3}, \sigma_{1}$ \\
\hline${ }^{*} 1979$ & 6.1 & 6.1 & 6.1 & 6.1 & 6.1 \\
\hline 1980 & 6.1 & 6.3 & 6.4 & 6.3 & 6.3 \\
\hline 1981 & 5.8 & 6.8 & 6.9 & 6.6 & 6.6 \\
\hline 1982 & 7.2 & 7.3 & 7.3 & 6.9 & 6.9 \\
\hline 1983 & 10.0 & 7.6 & 7.8 & 7.2 & 7.2 \\
\hline 1984 & 9.0 & 8.2 & 8.3 & 7.5 & 7.5 \\
\hline 1985 & 8.3 & 8.6 & 8.8 & 7.9 & 7.9 \\
\hline 1986 & 8.2 & 9.0 & 9.2 & 8.2 & 8.2 \\
\hline 1987 & 8.2 & 9.4 & 9.7 & 8.5 & 8.5 \\
\hline 1988 & 7.1 & 10.0 & 10.2 & 8.9 & 8.9 \\
\hline 1989 & 6.2 & 10.4 & 10.7 & 9.2 & 9.2 \\
\hline 1990 & 7.0 & 10.8 & 11.1 & 9.5 & 9.5 \\
\hline 1991 & 9.5 & 11.3 & 11.6 & 9.8 & 9.8 \\
\hline 1992 & 10.8 & 11.8 & 12.1 & 10.2 & 10.2 \\
\hline 1993 & 11.0 & 12.3 & 12.6 & 10.5 & 10.5 \\
\hline
\end{tabular}

* Dec Quarter the $A$ variable nor the $\sigma$ appeared in the preferred equation. 
It will be seen that the $U^{*}$ series shown in each of the three final columns has the same general character as the $U^{*}$ series based on Table 3; all four series show a steady upward movement in the natural rate over the period, only the extent of the rise varying from series to series. Thus the general character of the natural-rate series is the same regardless of the series used for $A$ and $\sigma$.

It is also clear that the relationship between the $U^{*}$ series and the $U$ series is largely independent of the series used for $A$ and $\sigma$; $U$ is above the $U^{*}$ only in 1983 and 1984 in one case and only in 1982 to 1985 , in the other two.

Thus the broad conclusion which emerges is that the discussion of section 3. 4, based on an unemployment equation using $A_{1}$ and $\sigma_{1}$, continues to hold when alternative series are used for $\mathrm{A}$ and $\sigma$ - our natural-rate results are remarkably robust with respect to the choice of series for these two unobservables.

\section{III.6 Comparison with US}

We now compare our Australian natural-rate results with those obtained for the US by Palley (1992). Palley's U* series is quarterly from 1957(1) to 1988(4) but it overlaps with our series sufficiently (the two series have 37 observations in common) for a meaningful comparison to be possible. Comparison with the other notable $U^{*}$ series produced for the US - by Lilien - is not possible, however, partly because Lilien's series is annual but mainly because it runs from 1948 to 1980 and so ends roughly where ours begins.

Palley's $U^{*}$ series is shown in Figure 2 together with the $U$ series. The method which he used to generate his $U^{*}$ series was, like ours, a variant of the method which Lilien (1982) proposed and used to derive his $U^{*}$ series for the US. Thus the method consists of estimating the unemployment equation implied by the Lilien labour-market model and then using the estimated equation to calculate the unemployment series that would have been observed if the pressure of aggregate demand had remained constant over the sample period.

It will be seen that, according to Palley, $\mathrm{U}^{*}$ remained roughly constant in the US over the entire period from 1957 to 1988 . In particular, it was stable throughout the 1980s. His results, therefore, contrast sharply with our Australian results as depicted in Figure 1. 
They also contrast with the US results obtained by Lilien. These are shown in Figure 3. It will be seen from the chart that, according to Lilien, the US natural rate began a long-term upward movement in the mid-1960s - a movement which continued at least until the end of the 1970s. This contradicts the Palley picture according to which the natural rate remained at the level of the 1950s at least until the end of the 1980s. In short, Palley's US results differ sharply both from our Australian results and the US results obtained by Lilien. ${ }^{11}$

It is not clear, however, that we are dealing with a genuine clash of results. The difficulty is that Palley's calculation of his $U^{*}$ series has three defects. Only when these have been removed can we be sure that the divergence between his results and those obtained by Lilien for the United States and those obtained by ourselves for Australia, is a real one.

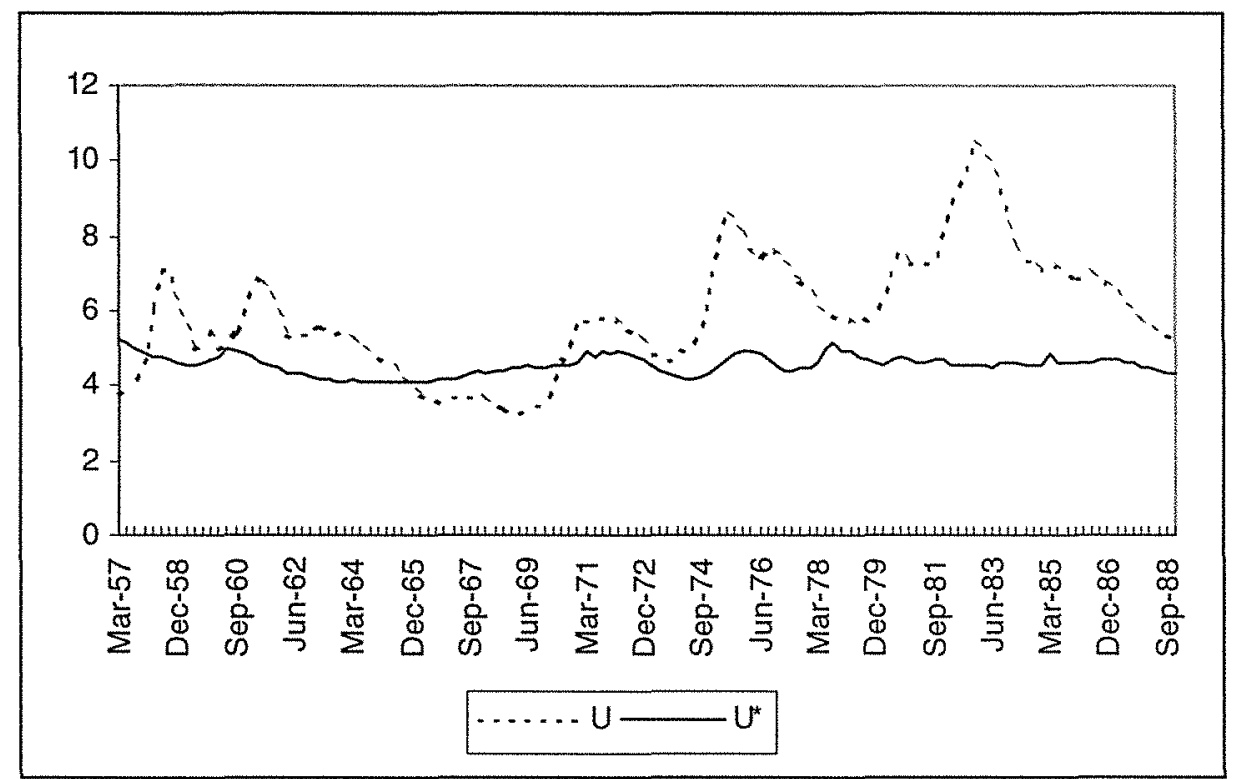

Figure 2. US Natural Rate: Palley

Two of Palley's three mistakes were mechanical in nature. The unemployment equation which he uses to generate his $U^{*}$ series resembles Lilien's in that it is a linear equation with the lagged dependent variable, the $\sigma$ and $\mathrm{A}$ variables, 
and a trend term, as explanatory variables. Both the $\sigma$ variable and the $\mathrm{A}$ variable appear unlagged and with one, two, and three lags. In generating his $U^{*}$ series Palley fails to include both the constant term in the equation and the trend term. In this respect he departs both from Lilien and ourselves. Lilien's estimated unemployment equation also includes a trend term and this is included, together with the constant term, in his calculation of $U^{*}$. Our unemployment equation has no trend term but, like Lilien, we include the constant term in the $\mathrm{U}^{*}$ calculation.

Palley's third mistake was conceptual in nature. In calculating $U^{*}$ from his unemployment equation Palley put all four of his A variables at zero. Thus his $U^{*}$ series became one for the unemployment rate that would have emerged if there had been no aggregate-demand pressure at any point in the sample period rather than a series for the unemployment rate that would have emerged if aggregate-demand pressure had remained unchanged throughout the sample period. Capturing the latter concept would have called for substituting a constant value for each of the four A variables; the sample mean of his A variable would have been the obvious choice.

Lilien also puts his aggregate demand variables at zero, as do we. In Lilien's case, however, the series used for A variable is such that there is nothing to choose between putting the $\mathrm{A}$ variable at zero and holding it constant at the sample mean since the series is the residual from an OLS regression. In our case, since the A variables appear in first-difference form, putting them at zero means requiring the pressure of aggregate demand to be constant, not non-existent.

Whether removing these defects would bring Palley's results into line with our Australian results and the US results obtained by Lilien, is a question which requires investigation. We propose to pursue the matter further with US data as part of our ongoing work on the natural-rate question. 


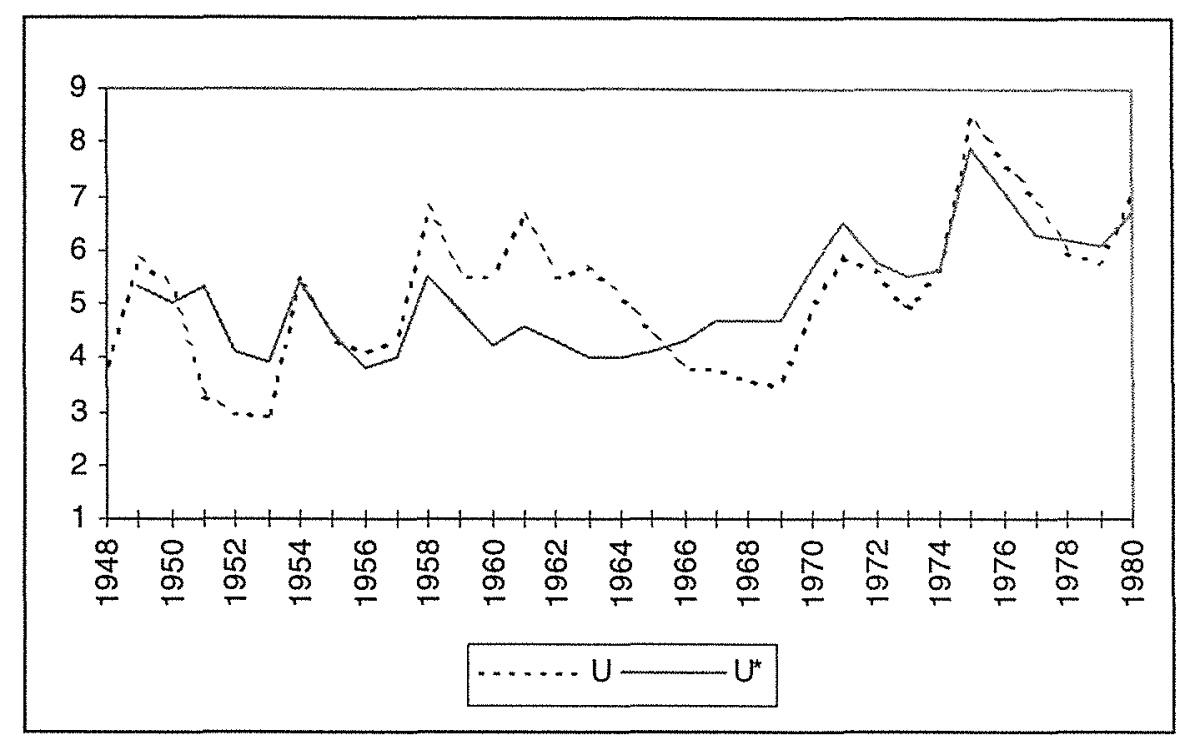

Figure 3: US Natural Rate: Lilien

IV Conclusion

Our concern in this paper has been with the natural rate of unemployment in Australia since the late 1970 s.

In Section 3 of the paper we presented an estimate of the natural rate by quarters for the period from 1979(4) to 1993(4). The method used to generate this quarterly series was essentially the method used by Lilien (1982) to derive an annual natural-rate series for the US for the years 1948 to 1980 and also by Palley (1992) to derive a quarterly series for the US for the period 1957(1) to 1988(3). The naturalrate series which we generated for Australia shows the natural rate rising steadily from 6.1 to 12.5 and the actual rate well below the natural rate throughout with the exception of the years 1982 to 1985 when $U$ was a little above $U^{*}$.

This result has considerable policy significance, which we detailed in Section 3. Faced by a steadily rising natural rate over which they had no control the task of the demand-management authorities was to keep the actual rate as far below the natural rate as possible for as long as possible, thus countering the upward thrust imposed on $U$ by the rising $U^{*}$. Our natural-rate series implies that they performed this task with notable success; $U$ was well below $U^{*}$ over much of the period to which our series relates. 
As for the future, our natural rate series implies that any improvement in Australia's unemployment record compared with the 1979 to 1993 period can come about in only one of two ways: either $\mathrm{U}^{*}$ must be cut back from its present high level or the demand management authorities must be even more successful than in the past in keeping $U$ below $U^{*}$. We believe that the former is the most promising route.

Our natural-rate results and their policy implications are particularly strong. We therefore tested them for robustness by repeating the estimation exercise with series for the unobservable exogenous variables, $\sigma$ and $A$, which differ from those used in the basic estimation. We found that the broad result (a steadily rising $U^{*}$ and a more or less permanently negative (U-U*)) held regardless of the series used for these two variables.

We also compared our results with those generated for the US by Palley (1990). We found that the two sets of results differ markedly but point to certain defects in Palley's application of the Lilien method which could well account for the difference. We propose following this up with US data as part of our continuing work on the natural-rate question.

We will also be re-examining the behaviour of Australia's natural rate since the late 1970s in the light of sources of natural-rate change other than the one which Lilien emphasised - the failure of the labour market to adjust smoothly to changes in the composition of aggregate demand. This will mean starting with a model of the labour market which differs in important respects from the Lilien model set out in section 2 of the paper and re-working the analysis from this new starting-point. 


\section{Appendix 1}

The VAR Model Used to Generate the $\sigma$ Series

As explained in the text, the measure of $\sigma$ used in this paper was generated by a 13-sector VAR model of the form,

$$
g_{i t}=\alpha_{0}^{i}+\sum_{j=1}^{J} \sum_{k=1}^{13} \beta_{j}^{i k} g_{k, t-j}+e_{i t}, \quad i=1,2, \ldots ., 13
$$

The parameters of the model were estimated using OLS and time-series data for the sectoral employment-growth variables, the $g_{i} s$. Employment growth for period $t$ was measured as the proportional change in employed persons from period $(t-1)$ to period t. Quarterly, seasonally-adjusted data for the period 1978(1) to 1994(1) were used. Data are from the ABS Monthly Labour Force survey and were obtained from the DXDATA data-base.

Prior to estimation the sectoral employment growth rates were tested for stationarity. Both the ADF and PP tests were performed with the following results ${ }^{12}$.

Stationarity Tests for Sectoral Employment Growth Rates

\begin{tabular}{|c|c|c|c|}
\hline Sector & ADF & PP & 10\% Critical Value \\
\hline 1 & 8.42 & 63.78 & 5.34 \\
\hline 2 & 8.62 & 61.56 & 5.34 \\
\hline 3 & 8.74 & 42.42 & 5.34 \\
\hline 4 & 4.07 & 18.32 & 5.34 \\
\hline 5 & 14.69 & 19.58 & 5.34 \\
\hline 6 & 4.99 & 21.22 & 5.34 \\
\hline 7 & 6.51 & 35.19 & 5.34 \\
\hline 8 & 5.20 & 43.16 & 5.34 \\
\hline 9 & 12.29 & 28.78 & 5.34 \\
\hline 10 & 3.88 & 24.18 & 5.34 \\
\hline 11 & 11.31 & 50.03 & 5.34 \\
\hline 12 & 6.38 & 52.27 & 5.34 \\
\hline 13 & 11.36 & 45.66 & 5.34 \\
\hline
\end{tabular}


It will be seen that all growth rates are stationary on the PP test and all but three on the ADF test. We regarded this result as providing convincing evidence that all growth rates were stationary.

Estimation required choice of lag length, $J$ for the VAR. This was carried out in RATS 3.11. Given the large number of sectors in the model and the relatively few observations (64), degrees-of-freedom considerations required a modest maximum lag-length. We considered a maximum value of $J$ of 4 and chose the lag length initially on the basis of the Akaike and Schwartz Information Criteria (see Judge et. al., 1988, pp.761-764). The AIC suggested a value of $\mathrm{J}=1$ while SIC suggested $\mathrm{J}=2$. A formal $\chi^{2}$ test of $J=1$ against $J=2$ resulted in a test statistic marginally significant at the 5\% level but not at the 1\%. A Breusch-Godfrey test of first- to fourth-order autocorrelation indicated that the VAR model with $J=1$ was substantially free of autocorrelation. Choice between $\mathrm{J}=1$ and $\mathrm{J}=2$ was, therefore, not clear-cut and we decided on the simpler case of $\mathrm{J}=1$. 
Appendix 2

The $\sigma, \mathbf{g}^{* *}, \mathbf{U}$ and $\mathbf{U} *$ Series

\begin{tabular}{|c|c|c|c|c|}
\hline Quarter & $\sigma$ & $g * *$ & U & $\mathrm{U}^{*}$ \\
\hline Dec-79 & 1.847 & 0.544 & 6.1 & 6.1 \\
\hline Mar-80 & 2.050 & 0.370 & 6.0 & 6.2 \\
\hline Jun-80 & 1.352 & -0.249 & 6.3 & 6.2 \\
\hline Sep-80 & 1.899 & 0.921 & 6.2 & 6.4 \\
\hline Dec-80 & 2.384 & -0.347 & 5.9 & 6.6 \\
\hline Mar-81 & 1.719 & 0.329 & 5.7 & 6.6 \\
\hline Jun-81 & 1.600 & 0.299 & 5.6 & 6.7 \\
\hline Sep-81 & 2.131 & -0.021 & 5.8 & 6.9 \\
\hline Dec-81 & 1.822 & -0.393 & 6.0 & 7.0 \\
\hline Mar-82 & 1.336 & 0.162 & 6.4 & 7.0 \\
\hline Jun-82 & 1.751 & 0.215 & 6.6 & 7.1 \\
\hline Sep-82 & 2.126 & -0.739 & 7.0 & 7.3 \\
\hline Dec-82 & 2.782 & -0.112 & 8.7 & 7.6 \\
\hline Mar-83 & 0.929 & -0.905 & 9.7 & 7.4 \\
\hline Jun-83 & 1.372 & -0.795 & 10.3 & 7.5 \\
\hline Sep-83 & 2.289 & -0.055 & 10.2 & 7.8 \\
\hline Dec-83 & 1.537 & -0.193 & 9.7 & 7.8 \\
\hline Mar-84 & 2.345 & 0.382 & 9.4 & 8.0 \\
\hline Jun-84 & 1.563 & 0.564 & 8.9 & 8.1 \\
\hline Sep-84 & 2.230 & 0.443 & 8.8 & 8.3 \\
\hline Dec-84 & 1.714 & -0.224 & 8.7 & 8.3 \\
\hline Mar-85 & 1.706 & 0.037 & 8.4 & 8.4 \\
\hline Jun-85 & 1.219 & 0.332 & 8.4 & 8.4 \\
\hline Sep-85 & 1.896 & 0.176 & 8.2 & 8.6 \\
\hline Dec-85 & 2.146 & 0.380 & 8.0 & 8.8 \\
\hline Mar-86 & 1.765 & 0.478 & 8.1 & 8.9 \\
\hline Jun-86 & 1.611 & 0.414 & 7.9 & 9.0 \\
\hline Sep-86 & 1.557 & 0.345 & 8.3 & 9.0 \\
\hline Dec-86 & 1.965 & -0.187 & 8.3 & 9.2 \\
\hline Mar -87 & 1.220 & -0.137 & 8.3 & 9.2 \\
\hline Jun-87 & 1.558 & -0.304 & 8.2 & 9.4 \\
\hline Sep-87 & 1.790 & 0.079 & 8.1 & 9.5 \\
\hline Dec-87 & 2.037 & 0.290 & 8.0 & 9.7 \\
\hline $\operatorname{Mar}-88$ & 1.810 & 0.497 & 7.4 & 9.8 \\
\hline Jun -88 & 2.168 & 0.342 & 7.4 & 9.9 \\
\hline Sep-88 & 1.987 & -0.004 & 7.1 & 10.0 \\
\hline Dec-88 & 1.266 & 0.131 & 6.6 & 10.0 \\
\hline Mar-89 & 1.674 & 0.479 & 6.7 & 10.2 \\
\hline Jun-89 & 1.629 & 0.470 & 6.3 & 10.3 \\
\hline Sep -89 & 1.964 & 0.293 & 6.0 & 10.5 \\
\hline $\operatorname{Dec}-89$ & 1.676 & 0.505 & 5.8 & 10.5 \\
\hline Mar-90 & 1.820 & -0.180 & 6.4 & 10.7 \\
\hline Jun-90 & 2.684 & -0.419 & 6.5 & 10.9 \\
\hline Sep-90 & 1.367 & 0.145 & 7.2 & 10.9 \\
\hline Dec-90 & 0.855 & 0.130 & 8.0 & 10.9 \\
\hline Mar-91 & 1.813 & -0.850 & 8.6 & 11.1 \\
\hline Jun-91 & 2.464 & -1.107 & 9.5 & 11.3 \\
\hline Sep-91 & 0.960 & -0.850 & 9.8 & 11.3 \\
\hline Dec-91 & 1.752 & -0.608 & 10.2 & 11.4 \\
\hline Mar-92 & 1.471 & -0.485 & 10.5 & 11.5 \\
\hline Jun-92 & 1.797 & -0.361 & 10.8 & 11.7 \\
\hline Sep -92 & 2.020 & -0.208 & 10.9 & 11.8 \\
\hline Dec-92 & 2.650 & -0.342 & 11.1 & 12.1 \\
\hline Mar-93 & 1.754 & -0.289 & 11.1 & 12.1 \\
\hline Jun-93 & 2.004 & 0.022 & 10.9 & 12.2 \\
\hline Sep-93 & 2.264 & -0.504 & 11.0 & 12.4 \\
\hline Dec-93 & 2.222 & 0.056 & 10.9 & 12.5 \\
\hline
\end{tabular}




\section{References}

Abraham, K.G. and L.F. Katz (1986), "Cyclical Unemployment: Sectoral Shifts or Aggregate Disturbances?", Journal of Political Economy, 94, 507-522.

Altonji, J.G. and J.C. Ham (1990), "Variations in Employment Growth in Canada: The Role of External, National, Regional and Industrial Factors", Journal of Labour Economics, 8, S198-S236.

Barro, R.J. (1977), "Unanticipated Money Growth and Unemployment in the United States", American Economic Record, 67, 101-115

Blanchard, O.J. and P. Diamond (1989), "The Beveridge Curve", Brookings Papers on Economic Activity, 1:1989, 1-60.

Brainard, S.L. and D.M. Cutler (1993), "Sectoral Shifts and Cyclical Unemployment Reconsidered", Quarterly Journal of Economics, 108, 219-243.

Campbell, J.Y. and P. Perron, (1991), "Pitfalls and Opportunities: What Macroeconomists Should Know about Unit Roots", NBER Macro Annual, 141-201.

Davidson, R. and J.G. MacKinnon (1993), Estimation and Inference in Econometrics, Oxford University Press, New York.

Davis, S.J. (1987), "Fluctuations in the Pace of Labour Reallocations", CarnegieRochester Conference Series on Public Policy, 27, 335-402.

Dickey, D.A. and W.A. Fuller (1981), "Likelihood Ratio Statistics for Autoregressive Time Series with a Unit Root", Econometrica, 49, 1057-1072.

Groenewold, N. and A.J. Hagger (1997), “The US Natural Rate: A 'Lilien' TimeSeries ", Discussion Paper, Department of Economics, University of Western Australia.

Jimeno, J.F. (1992), "The Relative Importance of Aggregate and Sector-Specific Shocks at Explaining Aggregate and Sectoral Fluctuations", Economics Letters, $39,381-385$.

Juhn, C., K.M. Murphy and R.H. Topel (1991), "Why Has the Natural Rate of Unemployment Increased over Time?", Brookings Papers on Economic Activity, 2:1991, 75-126.

Kennedy, P. (1992), A Guide to Econometrics, third edition, Blackwell, Oxford.

Layard, R. and S. Nickell (1985), "The Causes of British Unemployment", National Institute Economic Review, 111, 62-85. 
Lilien, D.M. (1982), "Sectoral Shifts and Cyclical Unemployment", Journal of Political Economy, 90, 777-794.

Loungani, P. (1986), "Oil Price Shocks and the Dispersion Hypothesis", Review of Economics and Statistics, 68, 536-539.

Loungani, P., M. Rush and W. Tave (1990), "Stock Market Dispersion and Unemployment", Journal of Monetary Economics, 25, 367-388.

Mills, T.C., G. Pelloni and A. Zervoyianni (1995), "Unemployment Fluctuations in the United States: Further Tests of the Sectoral Shifts Hypothesis", Review of Economics and Statistics, 77, 294-304.

Mishkin, F.S. (1982), "Does Anticipated Monetary Policy Matter? Further Econometric Results", American Economic Review, 72.

Mishkin, F.S. (1983), A Rational Expectations Approach to Macroeconomics : Testing Policy Ineffectiveness and Efficient-Markets Models, NBER and University of Chicago Press, Chicago.

Mishkin, F.S. (1995), "Symposium on the Monetary Transmission Mechanism", Journal of Economic Perspectives, 9, 3-10.

Murphy, K.M. and R.H. Topel (1987), "The Evolution of Unemployment in the United States: 1968-1985", NBER Macro Annual, 11-58.

Neelin, J. (1987), "Sectoral Shifts and Canadian Unemployment", Review of Economics and Statistics, 69, 718-723.

Norrbin, S.C. and D.E. Schlagenhauf (1988), "An Inquiry into the Sources of Macroeconomic Fluctuations", Journal of Monetary Economics, 22, 43-70.

Norrbin, S.C. and D.E. Schlagenhauf (1991), "The Importance of Sectoral and Aggregate Shocks in Business Cycles", Economic Inquiry, 29, 317-335.

Ooi, Soon Huay and N. Groenewold (1992), "The Causes of Unemployment in Australia 1966-1987", Australian Economic Papers, 77-93.

Oxley, L. and M. McAleer (1993), "Econometric Issues in Macroeconomic Models with Generated Regressors", Journal of Economic Surveys, 7, 1-40

Pagan, A. (1984), "Econometric Issues in the Analysis of Regressions with Generated Regressors", International Economic Journal, 25, 221-247.

Palley, T.I. (1992), "Sectoral Shifts and Cyclical Unemployment: A Reconsideration", Economic Inquiry, 30, 117-133. 
Parker, J. (1992), "Sectoral Unemployment in the United States: The Effects of Interindustry and Interregional Dispersion", Economic Inquiry, 101-116.

Phillips, P.C.B. and P. Perron (1988), "Testing for a Unit Root in Time Series Regression", Biometrika, 75, 335-346.

Reserve Bank of Australia (1993), "Towards Full Employment", Reserve Bank of Australia Occasional Paper No.12.

Sargent, T.J. and N. Wallace (1976), "Rational Expectations and the Theory of Economic Policy", Journal of Monetary Economics, 2, 169-183.

Samson, L. (1985), "A Study of the Impact of Sectoral Shifts on Aggregate Unemployment in Canada", Canadian Journal of Economics, 18, 518-530.

Siegloff, E.S. and N. Groenewold (1987), "Policy Ineffectiveness : Tests with Australian Data", Australian Economic Papers, 26, 179-187.

\section{End-notes}

1 Re-phrasing the question in this way implies that compositional changes are the only significant cause of changes in the natural rate. This is in line with Lilien's analysis. It should be recognised, however, that in the literature on unemployment changes in the natural rate have been attributed to a variety of causes other than compositional changes, eg. changes in employment taxes and in unemployment benefits.

2 Broadly speaking this was the conclusion reached by Lilien for the U.S. over the post-war period to 1980 .

$3 \quad$ Lilien (1982), p.780.

4 See, for example, Mishkin (1982, 1983) and Siegloff and Groenewold (1987).

More recent evidence may be found in the monetary transmission mechanism literature, eg. Mishkin (1995).

5 See, for example, Davidson and MacKinnon (1993), Chs 19, 20. 
The length of the sample period was dictated by the length of the $\sigma$ series.

7 The U series given in DXDATA data base is monthly. A quarterly series was derived by taking the observation for quarter $t$ to be the observation for the mid-month of the quarter.

$8 \quad$ See Dickey and Fuller (1981) and Phillips and Perron (1988).

$9 \quad$ See Kennedy (1992, Chapter 5) for a useful survey of specification issues including a discussion of the "Hendry approach".

10 See Pagan (1984) and Oxley and McAleer (1993) for an account of the problems and methods of overcoming them.

11 It is interesting that the application of the Lilien procedure to Canadian data by Samson(1985) produced results very similar to those of Lilien's for the US, viz. movements in the actual unemployment rate over the period were substantially explained by changes in the natural rate.

12 Lag length for autocorrelation adjustment in both cases were chosen separately for each sector. 